
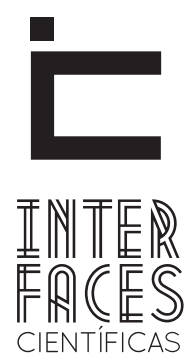

DIREITO

\title{
A REVISÃO JUDICIAL DAS LEIS EM RONALD DWORKIN EO CONTROLE DE CONSTITUCIONALIDADE BRASILEIRO
}

THE JUDICIAL REVIEW OF LAWS IN RONALD DWORKIN AND THE BRAZILIAN'S CONSTITUTIONAL CONTROL

\section{LA REVISIÓN JUDICIAL DE LAS LEYES DE RONALD DWORKIN Y CONTROL DE CONSTITUCIONALIDAD DE BRASIL}

\section{RESUMO}

0 artigo pretende explicar o judicial review de Ronald Dworkin e apresentar sua relação com o Controle de Constitucionalidade de acordo com o sistema jurídico brasileiro. A escolha do tema se deu em vista da importância e consequente influência que os ensinamentos de Dworkin tem na área do Direito. Para enfrentar o tema proposto, por meio de abordagem exploratória de dados levantados por revisão bibliográfica, serão explicados os conceitos fundamentais da teoria integrativa do direito criada por Dworkin. $\mathrm{Na}$ sequência, será abordado o conceito de democracia constitucional criado por Ronald Dworkin, explicando também sua teoria do controle judicial de leis. Ao final, será feita a relação entre a revisão judicial da forma defendida por Dworkin e o Controle de Constitucionalidade das leis existente no Brasil, chegando a conclusão que, na teoria, o sistema brasileiro é adepto à teoria dworkiniana, fato que não se repete na prática por conta do constante ativismo judicial da Suprema Corte brasileira.

\section{PALAVRAS-CHAVE}

Teoria do Direito. Ronald Dworkin. Judicial Review. Brasil. 


\section{ABSTRACT}

This article intends to explain the judicial review of Ronald Dworkin and present its relation with the Control of Constitutionality according to the Brazilian legal system. The choice of theme took place in view of the importance and consequent influence that the teachings of Dworkin have in the area of law. In order to face the proposed theme, through an exploratory approach of data raised by bibliographical revision, it will be explained the fundamental concepts of the integrative theory of law created by Dworkin. In the sequence it will be discussed the concept of constitutional democracy created by Ronald Dworkin, explaining also his theory of judicial control of laws. In the end it will be made the relation between the judicial review of the form defended by Dworkin and the Constitutional Control of the laws existing in Brazil arriving at the conclusion that, in theory, the Brazilian system is adept to the Dworkin's Theory fact that is not repeated in the practice because of the constant judicial activism of the Brazilian Supreme Court.

\section{KEYWORDS}

Theory of Law. Ronald Dworkin. Judicial Review.

Brazil.

\section{RESUMEN}

El artículo trata de explicar la revisión judicial de Ronald Dworkin y la presentación de su relación con el control de constitucionalidad de acuerdo con el sistema legal brasileño. El tema de la elección fue la importancia y la consiguiente influencia que las enseñanzas de Dworkin tienen en el área de la ley. Para abordar el tema, através de aproximación exploratoria a los datos recogidos por revisión de la literatura, se explicarán los conceptos fundamentales de la teoría integradora de la ley creada por Dworkin. Siguiendo se abordará el concepto de la democracia constitucional creado por Ronald Dworkin, también explica su teoría de las leyes judiciales. Al final, será realizada la relación entre el control judicial de manera defendido por Dworkin y el control de constitucionalidad de las leyes existente en Brasil, llegando a la conclusión de que, en teoría, el sistema brasileño es experto en la teoría dworkiniana, un hecho que no se repite en la práctica debido a la constante activismo judicial del Tribunal Supremo de Brasil.

\section{PALABRAS CLAVE}

Teoría del Derecho, Ronald Dworkin, la revisión judicial, Brasil. 


\section{INTRODUÇ̃̃̃O}

A doutrina de Ronald Dworkin é uma das mais importantes na área do Direito desde a segunda metade do século XX, e seus ensinamentos, mesmo que por muitas vezes de forma indireta, influenciam na doutrina e ordenamento brasileiro. A revisão judicial de leis por Tribunais é um dos pontos fortes de sua teoria e pode ser encontrada, sob determinados aspectos, no sistema de Controle de Constitucionalidade adotado pelo Brasil. É fundamental ressaltar que para a realização deste trabalho foram utilizados ensinamentos trazidos por Dworkin nas obras Taking Rights Seriously (1977), A matter of principle, Law's Empire (1986), Freedom's Law: The Moral Reading of the American Constitution (1996), Sovereign Virtue: The Theory and Practice of Equality (2000), Is Democracy Possible Here? Principles for a new political debate (2006), Justice for Hedgehogs (2011) e o artigo The Partnership Conception of Democracy (1998).

No decorrer deste artigo será demonstrado o que é o judicial review para Ronald Dworkin, suas principais características e como sua conceituação pode ser relacionada com o sistema de controle de constitucionalidade brasileiro. No entanto, para que essa exposição sobre a teoria dworkiniana possa ser realizada, primeiramente serão abordados alguns aspectos considerados relevantes para o bom entendimento do pensamento do autor.

De início, serão trazidos à baila alguns conceitos gerais da teoria do direito de Ronald Dworkin, principalmente no que diz respeito aos princípios e o conceito de teoria integrativa do Direito. Após isso, de forma mais aprofundada, tendo em vista a imensurável relevância do conceito de democracia para este trabalho, será explicado em tópico específico em que consiste o conceito constitucional de democracia criado por Dworkin.

A democracia dworkiniana tem especial importância quando se fala em judicial review, visto que conforme demonstrar-se-á, existem duas principais concepções de democracia: a procedimental e a substancial. Em se adotando apenas o primeiro conceito, o controle de constitucionalidade encontra fortes obstáculos, já de acordo com o segundo conceito ele é considerado instrumento fundamental para a garantia de direitos, assim, levando em conta a obra Freedom's Law especificar-se-á qual das concepções que o autor adota e ainda quais as consequências disso para seu judicial review.

Após isso, com base na literatura produzida pelo autor, demonstrar-se-á o que é a revisão judicial dworkiniana, como ela se dá, e principalmente, a intima relação que mantém com a teoria do direito de Dworkin no que tange basicamente dois aspectos: poder discricionário do juiz e a adoção de princípios. No último tópico, após realizada a construção da base teórica relacionar-se-á o judicial review dworkiniano com o sistema brasileiro de controle de constitucionalidade, demonstrando no que os dois sistemas se assemelham, onde se diferem para ao final dizer se a teoria de Dworkin é compatível com o sistema brasileiro.

Quanto a metodologia esta pesquisa é descritiva e exploratória pois visa a partir da análise de fatos colhidos por revisão bibliográfica analisar o conceito da revisão judicial de leis de Ronald Dworkin, passando pelos principais conceitos da Teoria do Direito do autor para ao final relacionar seu conceito de judicial review com o sistema de controle de constitucionalidade brasileiro.

\section{ASPECTOS FUNDAMENTAIS DA TEORIA DE RONALD DWORKIN}

Ronald Myles Dworkin viveu entre 1931 e 2013, foi um filósofo, jurista e professor norte-americano responsável por inúmeras obras que contribuíram para o avanço de conhecimento em diversas áreas. No entanto, como já foi exposto na introdução, neste trabalho o enfoque será em sua teoria do direito e principalmente na revisão judicial de leis defendida pelo autor.

De início, a fim de que se tenha uma visão completa da revisão judicial dworkiniana é necessário que se adentre alguns aspectos de sua teoria integrativa do direito. Dworkin desenvolve sua teoria como uma críti- 
ca ao positivismo jurídico, principalmente o desenvolvido por Herbert Lionel Albert Hart, que é estruturado em um sistema de normas primárias e secundárias, e sugere para isso uma forma de interpretação do direito a partir de um conjunto de princípios.

Essa árdua crítica ao positivismo legal, além de evidente em suas obras, é tópico que recebe atenção na Stanford Encyclopedia:

\begin{abstract}
Dworkin como o crítico mais significativo do positivismo, rejeita a teoria positivista em todos os níveis possíveis. Dworkin nega que pode haver qualquer teoria geral da existência e do conteúdo de direito; ele nega que as teorias locais dos sistemas jurídicos particulares podem identificar a lei sem recorrer a seus méritos morais, e ele rejeita o foco institucional inteiro do positivismo. A teoria do direito é para Dworkin uma teoria de como os casos devem ser decididos e começa, não com uma conta da organização política de um sistema legal, mas com um ideal abstrato regula as condições em que os governos podem usar força coercitiva sobre os seus sujeitos (GREEN, 2009, on-line). ${ }^{1}$
\end{abstract}

Para Dworkin, o direito é formado por regras e princípios, as primeiras são válidas ou não, já os princípios obtêm sua validade da praxe do tribunal ou de um conjunto de regras e tem sua validade declarada no caso concreto e somente nesta instância poderá ter seu peso avaliado (SAAVEDRA, 2006). Assim, os princípios não surgem de uma decisão específica do Poder Legislativo ou Executivo, e sim de uma construção de entendimentos daquilo que é "apropriado, desenvolvida pelos membros da profissão e pelo público ao longo do tempo" (DWORKIN, 2002, p. 64).

Como é de se esperar de um jurista norte-americano, Dworkin dedica grande parte de seus argumentos sobre teoria do direito para analisar a atividade dos juízes, e é justamente nesse ponto que o desenvolvimento de suas ideias tem início. 0 autor entende descabida a ideia po-

1 Tradução Livre: Dworkin, as positivism's most significant critic, rejects the positivist theory on every conceivable level. Dworkin denies that there can be any general theory of the existence and content of law; he denies that local theories of particular legal systems can identify law without recourse to its moral merits, and he rejects the whole institutional focus of positivism. A theory of law is for Dworkin a theory of how cases ought to be decided and it begins, not with an account of the political organization of a legal system, but with an abstract ideal regulating the conditions under which governments may use coercive force over their subjects. sitivista de que em hard cases $^{2}$ o juiz tenha poder discricionário para solucionar o caso, isto é, o conceito de que quando não se pode resolver um caso judicial com base em uma norma posta, o juiz tem poderes para criar um direito novo e o aplicar no caso em questão.

Em contrapartida à concepção positivista, Dworkin propõe que os hard cases devem ser resolvidos com base em um conjunto coerente de princípios que formam o ordenamento jurídico, rejeitando assim de forma veemente a possibilidade de conferir aos magistrados o poder discricionário da criação de direito:

Os juízes que aceitam o ideal interpretativo da integridade decidem casos difíceis tentando encontrar, em algum conjunto coerente de princípios sobre os direitos e deveres das pessoas, a melhor interpretação da estrutura política e da doutrina jurídica de sua comunidade. (DWORKIN, 1986, p. 255) 3

A professora Vera Karam de Chueri (2009, p. 52) faz leitura precisa sob esse aspecto da teoria dworkiniana:

Não há, pois, que se falar em discricionariedade no sentido (do positivismo de Hart) de que o juiz, em face de um caso controverso, cria o direito, na medida em que a ele é dado interpretar o conjunto de práticas que significam o direito como os precedentes, a legislação e os padrões morais socialmente compartilhados e, a partir deles construir a sua decisão baseada no princípio que melhor descreva essas práticas.

Na esteira da sua teoria da resposta certa, toda demanda judicial possui uma resposta, devendo ela ser construída de maneira coerente, pela escolha do princípio aplicável ao caso. Não qualquer princípio, mas aquele que aplicado ao caso o faça à luz do compromisso assumido de que todos devem ser tratados com igual respeito e consideração. Assim, o juiz, ao decidir o caso controverso, deverá interpretar os argumentos apresentados, levando em consideração não só as regras e os precedentes, mas também os padrões morais da sociedade e os seus próprios.

2 Os chamados casos difíceis é o termo utilizados por teóricos do direito onde existem disputas judiciais que não encontram no ordenamento jurídico vigente, a partir de um raciocínio lógico-dedutivo, uma solução aparente, fácil de encontrar.

3 Tradução Livre: Judges who accept the interpretative ideal of integrity decide hard cases by trying to find, in some coherent set of principles about people's right and duties, the best constructive interpretation of the political structure and legal doctrine of their community. 
Isso evidencia a concepção de direito como prática interpretativa de Dworkin, o que leva acrescentar à atividade judicial o princípio da integridade, que induz os juízes a definir direitos e deveres a partir de conceitos comuns da comunidade em questão, que reflitam sua concepção de justiça e equidade.

Ronald Dworkin ao mesmo tempo rejeita a ideia utilitarista por não achar uma definição para o que seria bem-estar coletivo, isto é, não é possível buscar por meio das decisões políticas o bem da comunidade como um todo se não é possível definir o que é exatamente esse "bem", ainda, muito menos é possível calcular os benefícios e os prejuízos dos indivíduos dentro de determinada sociedade para se determinar que a decisão tomada foi a melhor. 0 impacto disso em sua teoria do direito é que os direitos individuais são suficientes em si, isto é, não devem ser necessariamente submetidos aos critérios do bem-estar comum.

0 último aspecto fundamental da teoria de Dworkin para desenvolver o tema ora proposto reside na sua concepção constitucional de democracia. 0 autor analisa dois "modelos de concepção" de democracia, um maioritário e outro cooperativo.

\section{A CONCEPÇ̃̃̃O DE DEMOCRACIA CONSTITUCIONAL DE DWORKIN}

Democracia, devido principalmente à complexidade de seu conceito, é um tema geralmente mal compreendido, e quase sempre é entendido como "governo do povo" ou "governo da maioria". No entanto, Ronald Dworkin explica que essa premissa não é totalmente correta, em suma, democracia não é só a tomada de decisão pela maioria do povo, mas também tratar todos os membros da comunidade com igual cuidado e respeito ${ }^{4}$ (DWORKIN, 1996, p. 17).

Apesar de não ser o principal tema de Dworkin em seus escritos, a democracia toma grande importância seja na construção de seus raciocínios ou até mesmo em suas conclusões. Fato é que mesmo admitindo

4 Tradução Livre: all members of the community, as individuals, with equal concern and respect que "é uma questão de profunda controvérsia o que democracia realmente é" (DWORKIN, 1986, p. 15) ${ }^{5}$, o autor avança nos estudos sobre o assunto e constrói seu conceito constitucional de democracia.

Para chegar nesse conceito Dworkin primeiro divide a democracia em duas concepções: a maioritária e a cooperativa. A democracia majoritária tem base na ideia de que a decisão política deve coadunar com a vontade da maioria, isto é, o processo de tomada de decisão para ser considerado democrático deve obedecer ao que a maioria dos indivíduos deseja. 0 problema disso, na ótica do autor, é que as minorias - votos-vencidos - acabam sendo massacrados pela maioria e mesmo assim o processo continua sendo considerado democrático.

Sem prejuízo dessa ideia, Ronald Dworkin faz a ressalva de que os defensores da democracia majoritária admitem existir determinados direitos individuais que obrigatoriamente devem ser respeitados pela maioria, e inclusive não negam sua proteção, no entanto, isso se dá em caráter excepcional. Ainda, quando acontece uma dessas exceções onde um direito de minoria deve ser preservado mesmo contra a vontade da maioria, para os majoritaristas estar-se-á diante de uma situação injusta.

\begin{abstract}
Quase todos pensamos que a democracia é uma forma de governo valiosa, ou mesmo indispensável. Achamos que vale a pena lutar, e talvez até morrer, para protegê-la. Precisamos de uma concepção de democracia que se encaixe nessa noção de valor da democracia: precisamos de uma noção que nos mostre o que há de tão bom na democracia. A concepção maioritarista não faz isso, porque não há nada que possua valor inerente em um processo que permite a um grande número de pessoas impor sua vontade a um número menor. 0 governo da maioria não é justo nem valioso em si. Só é justo e valioso quando atende a determinadas condições, entre elas as exigências de igualdade entre os participantes do processo político, por meio do qual se definirá a maioria. (DWORKIN, 2005, p. 509-510).
\end{abstract}

De qualquer forma, o autor rechaça a concepção majoritária de democracia e faz isso afirmando que não existe direito ou ideologia capaz de justificar a supressão, por vontade da maioria, de direitos individuais

5 Tradução Livre: It is a matter of deep controversy what democracy really is. 
da minoria. Ao mesmo tempo, Dworkin tem sua concepção cooperativa ou constitucional de democracia.

Como o próprio autor em sua recente obra Justice for Hedgehogs:

O conceito cooperativo de democracia é diferente: ele defende que autogoverno significa governo não pela maioria das pessoas exercendo autoridade sobre todos mas sim pelas pessoas como um todo atuando como parceiros. Isso deve inevitavelmente ser uma parceria que se divide na política vez que unanimidade é rara nas comunidades políticas de qualquer tamanho ${ }^{6}$. (DWORKIN, 2011, p. 384).

Democracia cooperativa vem da ideia de que os indivíduos de determinada sociedade, ao realizarem suas decisões políticas irão decidir pensando na comunidade como um todo, não apenas em uma maioria, e mais, seus atos devem ser pautados na igualdade de respeito entre seus membros. A exigência da igualdade toma fundamental importância por seus desdobramentos, vejamos bem, ao se ter respeito e "preocupação" igual para todos os membros de uma sociedade, automaticamente os interesses da minoria devem também ser levados em conta, sob pena de se chegar em uma decisão não democrática mesmo quando tomada pela maioria dos indivíduos ou de seus representantes, isto é "na visão cooperativa, a comunidade que ignora os interesses de uma minoria ou outro grupo é só por esse motivo não democrática mesmo que eleja representantes de maneira impecavelmente majoritária"7 (DWORKIN, 2006, p. 131).

Dessa forma, é essencial para a democracia que o povo se autogoverne, no entanto para Dworkin podemos apenas aceitar essa ideia sob o preceito de que democracia é algo mais que a regra maioritária, de fato, ele a defende como uma espécie de parceria entre os

6 Tradução Livre: The partnership conception of democracy is different: it holds that selfgovernment means government not by the majority of people exercising authority over everyone but by the people as a whole acting as partners. This must inevitably be a partnership that divides over policy, of course, since unanimity is rare in political communities of any size. But it can be a partnership nevertheless if the members accept that in politics they must act with equal respect and concern for all the other partners.

7 Tradução Livre: On the partnership view, a community that steadily ignores the interests of some minority or other group is just for that reason not democratic even though it elects officials impeccably majoritarian means cidadãos onde se assegura tanto os direitos individuais como procedimentos majoritários (DWORKIN, 1998). As duas concepções de democracia ora apresentadas partem do mesmo ponto, mas acabam tomando caminhos diferentes, e de forma contemporânea bem as define Scott M. Noveck (2008, p. 407):

A primeira concepção enxerga a democracia como uma forma de bem intrinseco, baseada no direito do povo de ser responsabilizado por qualquer lei que os atinga, mesmo que a lei que eles escolham seja longe do ideal. A segunda concepção defende a democracia como um bem procedimental - isto é, como uma forma de governo que prefere políticas que se adequem a entendimentos do que é bom ou justo - mas que autorize desvios do ideal majoritário desde que esses desvios possam promover justiça, eficiência ou outro valor ${ }^{8}$.

A concepção majoritária dá mais importância a como se decide do que o quê se decide, e isso em termos mais contemporâneos podemos chamar de visão procedimental da democracia. Já a democracia cooperativa também se preocupa com a forma como se decide, no entanto dá igual importância ao teor da decisão, e brada pela igualdade de respeito durante todo o processo de decisão, conferindo assim maior importância aos direitos fundamentais, possibilitando a convivência entre governo de maioria e direitos da minoria, isso, também de forma contemporânea, chamamos de visão substancial da democracia.

O contraponto dessas concepções gera reflexões valiosas nas obras de Dworkin e traz à tona o tema central deste artigo que é sua concepção da revisão judicial das leis que " não é antidemocrática mas, ao contrário, é praticamente indispensável para a democracia" ${ }^{\circ}$ (DWORKIN, 1996, p. 7), e a exposição torna relevante principalmente diante das inúmeras críticas de expoentes doutrinários como John Hart Ely e Michael Waldron, 8 Tradução Livre: The first view sees democracy as a form of intrinsic good, based on the right of the people to be responsible for any law which binds them, even if the laws they choose are far from ideal. The second view advocates democracy as an instrumental good-that is, as being the form of government most likely to select policies that conform to some external understanding of what is good or just-but authorizes deviations from the majoritarian or participatory ideal insofar as these deviations can better promote justice, efficiency, or some other value.

9 Tradução Livre: Is not antidemocratic but, on the contrary, is practically indispensable to democracy 
que mesmo ao mesmo tempo que defendem a existência da revisão judicial a consideram antidemocrática.

\section{A REVISÃO JUDICIAL DAS LEIS EM DWORKIN: INSTRUMENTO DE FORTALECIMENTO DA DEMOCRACIA E DE GARANTIA DE DIREITOS}

\begin{abstract}
Se queremos a revisão judicial - se não queremos anular Marbury contra Madison - devemos então aceitar que o Supremo Tribunal deve tomar decisões políticas importantes. A questão é que motivos, nas suas mãos, são bons motivos. Minha visão é que o Tribunal deve tomar decisões de princípio, não de política - decisões sobre que direitos as pessoas têm sob nosso sistema constitucional, não decisões sobre como se promove melhor o bem-estar geral -, e que deve tomar essas decisões elaborando e aplicando a teoria substantiva da representação, extraída do princípio básico de que o governo deve tratar as pessoas como iguais. (DWORKIN, 2001, p. 100-101).
\end{abstract}

Os defensores de cada uma das correntes de democracia que foram expostas entram em conflito também no que diz respeito a compatibilidade da revisão judicial das leis e o sistema democrático. A base do argumento para aqueles que veem a democracia de forma procedimental reside no fato de que as decisões políticas são tomadas pela maioria de representantes eleitos por votos da maioria da população, e o fato de que a revisão de leis é feita por juízes que, em regra, não são eleitos, a tornaria antidemocrática, isso é chamado de objeção contramajoritária ${ }^{10}$.

Dworkin entende de forma diferente, diz que a revisão judicial longe de ser antidemocrática fortalece a democracia sob uma ótica substancialista, visto que o controle de constitucionalidade seria a última trincheira para a defesa de direitos fundamentais de

10 “A questão mais profunda é que o controle de constitucionalidade (judicial review) é uma força contramajoritária em nosso sistema. [...] Quando a Suprema Corte declara inconstitucional um ato legislativo ou um ato de um membro eleito do Executivo, ela se opõe à vontade de representantes do povo, o povo que está aqui e agora; ela exerce um controle, não em nome da maioria dominante, mas contra ela. [...] 0 controle de constitucionalidade, no entanto, é o poder de aplicar e interpretar a Constituição, em matérias de grande relevância, contra a vontade da maioria legislativa, que, por sua vez, é impotente para se opor à decisão judicial” (BICKEL,1986 apud BARROSO, 2012). minorias. Luís Fernando Sgarbossa (2013, p. 144), no mesmo sentido que Dworkin anota que "estas matérias, por sua relevância, não poderiam, sem risco, ficar sujeitas ao processo político ordinário, não sendo prudente sustentar que possam ser restringidas e modificadas ao talante das maiorias ocasionais".

Ronald Dworkin enfatiza que os Estados Unidos é uma sociedade mais justa, pois tem meios judiciais de se proteger a sua Constituição (DWORKIN, 1996, p. 356), no entanto o assunto não é tão simples quanto parece. A revisão judicial para Dworkin não pode ser feita de qualquer forma, existem dois pontos importantes que devem ser observados: competência e parâmetros.

Em primeiro lugar, Dworkin entende que a revisão judicial deve ser realizada por juízes, pois estes não estão em situação inferior aos legisladores para decidir questões políticas de princípios, afinal, uma análise pormenorizada de reivindicação de direito é, sem dúvidas, melhor decidida no campo jurídico do que no campo político. Além disso, os direitos da minoria têm maiores chances de serem resguardados por juízes, pois estes estão livres de pressões externas de uma maioria, coisa que não acontece com os membros do poder legislativo:

\footnotetext{
Existem, primeiramente, razões institucionais para que uma decisão legislativa sobre direitos tenha probabilidade de ser mais exata que uma decisão judicial? É difícil avaliar a questão da exatidão abstratamente, isto é, separadamente de alguma teoria particular de direitos. Mas não consigo imaginar em que argumento se poderia pensar para demonstrar que decisões legislativas sobre direitos tem mais probabilidade de serem corretas que decisões judiciais.

[...] Mas não conheço nenhuma razão pela qual seja mais provável um legislador tem opiniões mais precisas sobre o tipo de fatos que, sob qualquer concepção mais precisas sobre o tipo de fatos que, sob qualquer concepção plausível de direitos, seriam relevantes para determinar o que são os direitos das pessoas. [...] Mas a técnica de examinar uma reivindicação de direito no que diz respeito à coerência especulativa é muito mais desenvolvida em juízes que em legisladores ou na massa dos cidadãos que elegem os legisladores.

Além disso, em alguns casos, o público que elege legisladores irá, com efeito, participar da discussão sobre se alguém tem ou não direito a algo, pois os interesses do público opõem-se à concessão de um direito. (DWORKIN, 2001, p. 26-27).
} 
No entanto, apesar de defender a atuação dos juízes na revisão judicial, Dworkin é enfático ao dizer que essa atuação acontece de forma limitada e pontual, pois "se todo o poder político fosse transferido para os juízes, a democracia e a igualdade do poder político seriam destruídas. Mas agora estamos considerando apenas uma classe pequena e especial de decisões políticas" (DWORKIN, 2001, p. 30).

0 segundo ponto diz respeito aos parâmetros que um juiz deve utilizar para decidir sobre a revisão judicial de leis, em outras palavras, quais seriam os critérios que um juiz deve utilizar para decidir se determinada norma deve ser revisada ou não?

De início, é importante registrar que Dworkin tendo em vista os próprios preceitos defendidos em sua teoria - em momento algum considera que a decisão da revisão judicial pode ser tomada com base na discricionariedade do próprio magistrado, como defendem os positivistas.

Além disso, não devem também tomar decisões, tendo como fundamento questões de moralidade pessoal, ou de foro íntimo, sob pena de cair em apenas uma diferente roupagem de uma concepção de democracia maioritarista. Dworkin defende também que a decisão não deve ser pautada em argumentos políticos ${ }^{11}$ pois estes são exclusividade dos poderes executivo e legislativo, que são eleitos democraticamente e diretamente pelo povo.

0 autor entende que decisões de revisão judicial de leis devem ter como parâmetro apenas princípios, e não política, isto é, a revisão judicial se resume apenas em um vigoroso debate a fim de dizer se determinada lei está condizente ou não com os princípios trazidos pela Constituição, sem se preocupar na promoção de bem-estar social ou qualquer tipo de consequencialismo. Nas palavras do próprio autor:

A revisão judicial é uma característica distintiva de nossa vida política, invejada e cada vez mais copiada em outros lugares. É uma característica penetrante porque obriga o debate político a incluir o argumento acerca do princípio, não apenas quando um caso vai ao Tribunal, mas muito antes e muito depois. Esse debate

$11 \mathrm{Em}$ Levando os Direitos a Sério Dworkin define policy como o padrão que estabelece o objetivo a ser alcançado, como por exemplo uma melhoria em algum aspecto económico, político ou social da comunidade (DWORKIN,2002, p. 36) não é necessariamente muito profundo nem é sempre muito vigoroso. É não obstante, valioso. Nas últimas décadas, os norte-americanos debateram a moralidade da segregação racial e chagaram a um grau de consenso, no nível do princípio, que antes se julgava impossível. Esse debate não teria tido o caráter que teve, não fosse o fato e o simbolismo das decisões do Tribunal. (DWORKIN, 2001, p. 102).

Na visão de Dworkin a revisão judicial é método imprescindível para a garantia de direitos fundamentais a fim de proteger e fortalecer a democracia em sua concepção substancialista, ou em suas próprias palavras, concepção constitucional. Nesse entendimento, o autor diz ser adequado que decisões tomadas por representantes da maioria sejam revistas pelo Poder Judiciário a fim de garantir direitos de minoria.

No entanto, deve ser pontuado que esse processo não é regra, e deve ser feito com parâmetros, de forma controlada e racional, e o meio que o autor defende para se fazer isso é que essas decisões sejam tomadas com base em princípios trazidos pelo sistema constitucional.

\section{JUDICIAL REVIEW DWORKINIANO E O CONTRO- LE DE CONSTITUCIONALIDADE BRASILEIRO}

A Constituição Republicana de 1891 criou o Supremo Tribunal Federal, acontecimento que rompeu com a antiga concepção de que o Poder Judiciário era mero acessório do Poder Executivo, e que deveria ficar fora de questões com grande repercussão pois não poderia sob nenhum pretexto interferir em questões políticas (KOERNER, 1991).

A influência norte-americana com a ideia de uma Suprema Corte com o dever de ser verdadeira "guardiã” da Constituição é inegável, mesmo o Brasil tendo seu ordenamento jurídico com heranças romano-germânicas (Civil Law). Isso acabou dando ensejo à judicialização da política, e o caso brasileiro - mais emblemático - que inaugurou essa possibilidade foi o da autonomeação ao cargo de Presidente da República do Marechal Floriano Peixoto, que gerou uma crise jurídico-política no país. 
Diante do cenário calamitoso, militares contrários ao Marechal redigiram carta-manifesto, repudiando a atitude, o que resultou em exonerações. Foi então que o advogado Rui Barbosa interpôs na Justiça Federal ações para anular os atos de demissão dos militares, e mesmo sendo totalmente inédita a procedência desse tipo de ação, em 1895 se teve a primeira decisão favorável à anulação, sendo posteriormente ratificada pelo Supremo Tribunal Federal, da forma que hoje muitos chamam este caso de "Marbury vs Madison brasileiro".

A Constituição de 1988, foi o marco de transição entre o regime ditatorial militar inaugurado na década de 1960 e terminado em 1984, trouxe uma forma diferente de Estado de Direito onde se buscou ao mesmo tempo assegurar direitos fundamentais, garantir a expressão de valores políticos da sociedade como um todo e disciplinar as "regras” do jogo democrático. Além disso, a Carta de 1988 prevê expressamente o Controle de Constitucionalidade a ser realizado pelo Supremo Tribunal Federal, inclusive, indicando o rol de seus legitimados, ficando evidente que o ordenamento brasileiro admite o judicial review.

Como bem lembra Luís Roberto Barroso (2012), a Constituição de 1988 manteve o sistema eclético, híbrido ou misto, combinando o controle por via incidental e difuso (sistema americano), que vinha desde o início da República, com o controle por via principal e concentrado, implantado com a EC n. 16/65 (sistema continental europeu).

Superada a questão quanto a admissibilidade do Controle de Constitucionalidade no ordenamento brasileiro, para que se possa chegar a uma conclusão sobre a relação da teoria de Dworkin e o sistema do Brasil devemos analisar a compatibilidade da democracia constitucional dworkiniana com a concepção brasileira de democracia.

Nesse ponto é importante transcrever o preâmbulo da Constituição de 1988, que mesmo não tendo força normativa, deixa clara as pretensões da carta constitucional:

Nós, representantes do povo brasileiro, reunidos em Assembleia Nacional Constituinte para instituir um Estado Democrático, destinado a assegurar o exercício dos direitos sociais e individuais, a liberdade, a segurança, o bem- -estar, o desenvolvimento, a igualdade e a justiça como valores supremos de uma sociedade fraterna, pluralista e sem preconceitos, fundada na harmonia social e comprometida, na ordem interna e internacional, com a solução pacífica das controvérsias, promulgamos, sob a proteção de Deus, a seguinte CONSTITUIÇÃO DA REPÚBLICA FEDERATIVA DO BRASIL. (BRASIL, 1988, on-line).

Os termos do preâmbulo transcrito mostram extensa quantidade de direitos que se pretende garantir, sem contar ainda o extenso rol de direitos fundamentais que a Constituição dispõe em todo seu corpo deixam claro que ela adota a concepção substancialista de democracia, em outras palavras, a concepção defendida por Ronald Dworkin.

É importante registrar que a diferença de sistema legal entre o Brasil - Civil Law - e os Estados Unidos Common Law - que foi onde Dworkin desenvolveu sua teoria não dificulta a análise ora realizada, pois primeiro como se viu, o sistema de controle de constitucionalidade brasileiro teve forte influência norte-americana, e segundo a concepção de democracia independe da origem do sistema legal. No entanto, mesmo que aparentemente o judicial review brasileiro seja compatível com os preceitos de Ronald Dworkin, não se pode dizer, que na situação atual, o Brasil siga sua teoria.

A grande diferença esbarra na onda de ativismo judicial que vem tomando conta do Supremo Tribunal Federal nas últimas décadas, e veja bem, aqui não se faz nenhum juízo de valor quanto a isso, apenas o mencionamos para fim de comparação com a teoria dworkiniana. Em diversas situações vemos a Suprema Corte brasileira extrapolar - por conta da ineficiência do Poder Legislativo - o limite de guardião da constituição e acabar tomando a frente de decisões que, em tese, não pertencem a sua alçada.

Dworkin defende uma "leitura moral" da Constituição, no entanto o cerne de sua teoria reside na concepção de que juízes não detém poder discricionário para decidir, aliás, essa é uma de suas maiores críticas ao positivismo. Como já foi exposto, os magistrados devem pautar suas decisões - inclusive aquelas de aplicação da Constituição - em princípios.

Assim, o autor propõe que ao mesmo tempo que as 
decisões políticas devem ser exercidas em regra pela Poder Legislativo, deve este seguir as disposições constitucionais a fim de garantir direitos fundamentais, no entanto, serve o Poder Judiciário para, em caso de desrespeito à Constituição e/ou violação de direitos, atuar revisando decisões para resguardar os direitos violados e garantir o tratamento com igual respeito a todos os cidadãos, sem nenhum tipo de discriminação.

\section{CONSIDERACÕES FINAIS}

Ronald Dworkin não desponta como um dos principais teóricos contemporâneos do direito à toa, suas ideias são fortes e agregam muito ao conhecimento jurídico e seus ensinamentos ecoam em diversos ordenamentos, inclusive o brasileiro. 0 autor, com sua teoria integrativa do direito influencia principalmente o ordenamento norte-americano.

A necessidade de se tratar os cidadãos (e suas opiniões) com igual respeito toma importante papel em suas obras, sem contar que o autor se destaca pelas árduas críticas ao positivismo, principalmente o de Hart, e diz, em suma, que o direito é feito também de princípios. Esses princípios não se originam de uma decisão única, ou específica, mas sim são uma construção da própria sociedade, e devem ser levados em conta nas decisões judiciais, aliás, são a eles que o juiz deve se socorrer em casos difíceis de se resolver, os hard cases.

Dworkin ensina que devemos encarar a democracia sob o aspecto substancial, ou como ele mesmo define, sob uma ótica constitucional, onde o resultado do processo político deve ser considerado mais importante do que o procedimento em si, o autor defende assim a defesa dos direitos individuais/fundamentais de vontades de maiorias eventuais. Com a adoção dessa "democracia constitucional” Dworkin consegue relacionar o constitucionalismo e a democracia em caráter de complementariedade, um apoiando o outro para se garantir direitos aos indivíduos:

Com a democracia, apreendemos que os direitos se reinventam e, com o constitucionalismo, que eles se (auto) limitam. A partir desta tensão, o papel do direito e dos direitos em uma sociedade complexa como a brasileira é afirmar, como o faz Dworkin para a sociedade norte-americana, que só há democracia porque há constitucionalismo e vice-e-versa. (CHUEIRI, 2009, p. 65).

$\mathrm{Na}$ esteira dessa ideia de garantia de direitos, o judicial review surge como importante instrumento de controle das decisões políticas a fim de que direitos fundamentais não sejam violados, isto é, por meio do controle de constitucionalidade pode o Poder Judiciário - no caso da teoria dworkiniana - declarar inconstitucional atos emanados pelos demais poderes que não estejam em conformidade com o que prevê a Constituição, que por sua vez é a instrumentalização das conquistas de direito da comunidade como um todo.

Posso ter dado a impressão de que a democracia e o Estado de Direito são conflitantes. Não é isso; pelo contrário, esses dois importantes valores políticos estão enraizados em um ideal mais fundamental, o de que qualquer governo aceitável deve tratar as pessoas como iguais. 0 Estado de Direito, na concepção que defendo, enriquece a democracia ao acrescentar um fórum independente, um fórum do princípio, e isso é importante, não apenas porque a justiça pode ser feita ali, mas porque o fórum confirma que a justiça, no fim, é uma questão de direito individual, não, isoladamente, uma questão do bem público. (DWORKIN, 2001, p. 38-39),

Em resposta àqueles que argumentam que a revisão judicial é uma violação à democracia, sob o argumento que possibilita indivíduos não eleitos por voto popular decidir a respeito de decisões políticas tomadas por agentes eleitos democraticamente Dworkin afirma com propriedade que legisladores não são mais preparados que juízes para decidirem questões de direito, ainda mais quando se discute interesses de uma minoria. o judicial review cria o fórum do princípio, onde questões podem ser debatidas à luz do direito e se tem a oportunidade de aperfeiçoar a democracia e o Estado Constitucional, vez que direitos individuais - dito fundamentais - podem ser assegurados inclusive às minorias.

O sistema de controle de constitucionalidade brasileiro teve inspiração direta no norte-americano, e mesmo que as origens de ambos os ordenamentos 
sejam diversas, isto é, o brasileiro adotando o civil law e o norte-americano adotando o common law, a comparação entre os dois é pertinente. No entanto, deve ser feita a ressalva de que a teoria dworkiniana do judicial review está presente apenas formalmente na Constituição Federal de 1988.

Isso acontece, pois, a Constituição de 88 tem caráter garantista, e busca a promoção de direitos fundamentais inclusive com a possibilidade da atuação do Poder Judiciário para que esses direitos sejam assegurados, no entanto, em decorrência de um Poder Legislativo ineficiente, o que se vê na prática é que o Supremo Tribunal Federal - órgão responsável pelo Controle de Constitucionalidade Concentrado - vem se revestindo de um ativismo judicial que não é compatível com as ideias defendidas por Dworkin.

0 autor defende o judicial review pautado em princípios que são previamente estabelecidos, e o processo como todo é conduzido por juízes de forma racional e controlada; é por isso, que no momento em que o Supremo Tribunal Federal do Brasil passa a aceitar argumentos demasiadamente genéricos para promover o controle de constitucionalidade - e suprir a mora legislativa -, a revisão judicial de Ronald Dworkin passa a ser compatível apenas na teoria com o ordenamento brasileiro.

\section{REFERÊNCIAS}

\section{BARROSO, Luís Roberto. 0 controle de constitucionalidade no direito brasileiro. São Paulo: Saraiva, 2012.}

BICKEL, A. The least dangerous branch. 2.ed. Indianapolis: Bobbs-merril Co., 1986

\section{BRASIL. Constituição da República Federativa do}

Brasil. 1988. Disponível em: <http://www.planalto. gov.br/ccivil_03/constituicao/constituicaocompilado. html>. Acesso em: 4 abr. de 2016.

CHUEIRI, Vera Karam de. Como levar o Supremo Tribunal Federal a sério: Sobre a suspensão de Tutela
Antecipada n. 91. Revista Direito GV, n.5. São Paulo: Jan-Jun 2009. p.45-66.

DWORKIN, Ronald. Freedom's Law The Moral Reading of the American Constitution. Cambridge: Harvard University Press, 1996.

DWORKIN, Ronald. Law's Empire. Cambridge: Harvard University Press, 1986.

DWORKIN, Ronald. A virtude soberana: A teoria e a prática da igualdade. São Paulo: Martins Fontes, 2005.

DWORKIN, Ronald. Is democracy possible here? Principles for a new political debate. Oxford: Princeton University Press, 2006.

DWORKIN, Ronald. Levando os direitos a sério. São Paulo: Martins Fontes, 2007.

DWORKIN, Ronald. Justice for hedgehogs.

Cambridge: Harvard University Press, 2011.

DWORKIN, Ronald. The partnership conception of democracy, 86 California Law Review. 453 (1998).

DWORKIN, Ronald. Uma questão de princípio. São Paulo: Martins Fontes, 2001.

GREEN, Leslie. Legal positivism. The Stanford Encyclopedia of Philosophy (Fall 2009 Edition), Edward N. Zalta (Ed.). Disponível em: <http://plato. stanford.edu/archives/fall2009/entries/legalpositivism/>. Acesso em: 5 maio 2016.

KOERNER, Andrei. Judiciário e cidadania na Constituição da República Brasileira. São Paulo: DCP-USP/Hucitec, 1998.

NOVECK, Scott M. Is Judicial Review Compatible with Democracy? Cardozo Public Law, Policy \& Ethics Journal, São Francisco, v.6, n.2, p.401, 2008. 
SGARBOSSA, Luís Fernando; et al . Uma crítica à objeção contramajoritária ao controle judicial de constitucionalidade. In: X Simpósio Nacional de Direito Constitucional - ABDConst, 2013, Curitiba, PR. Anais do X Simpósio Nacional de Direito Constitucional.

Curitiba: ABDCONST, 2013. v.1. p.132-151
SVAAEDRA, Giovani Agostini. Jurisdição e

Democracia: uma análise a partir das teorias de Jurgen Habermas, Robert Alexy, Ronald Dworkin e Niklas Luhmann. Porto Alegre: Livraria do Advogado, 2006.
Data da submissão: 19 de outubro de 2016

Avaliado em: 10 de novembro de 2016 (Avaliador A) Avaliado em: 22 de dezembro de 2016 (Avaliador B) Aceito em: 26 de dezembro de 2016
1 Advogado; Pós-Graduando em Direito Processual Civil pelo CERS; Mestrando em Direito pela Universidade Federal de Mato Grosso do Sul; Graduado em Direito pela Universidade Federal de Mato Grosso do Sul. E-mail: luiz_ormay@hotmail.com

2 Advogada; Doutora e Mestre em Direito pela Pontifícia Universidade Católica de São Paulo - PUC/SP; Especialista em Direito Penal Econômico pela Universidade de Coimbra; Professora Colaboradora do Curso de Mestrado em Direitos Humanos da Universidade Federal de Mato Grosso do Sul - UFMS; Professora da Graduação da Universidade Federal de Mato Grosaso do Sul - UFMS em Campo Grande-MS, da Universidade Católica Dom Bosco - UCDB e da Escola Superior da Magistratura de Mato Grosso do Sul (ESMAGIS), vinculada a Faculdade de Direito da Universidade Federal de Mato Grosso do Sul. E-mail rejane.arruda@hotmail.com 